\title{
Da política tradicional de tratamento do lixo à política de gestão de resíduos sólidos As novas prioridades
}

$\star$ Jacques Demajorovic

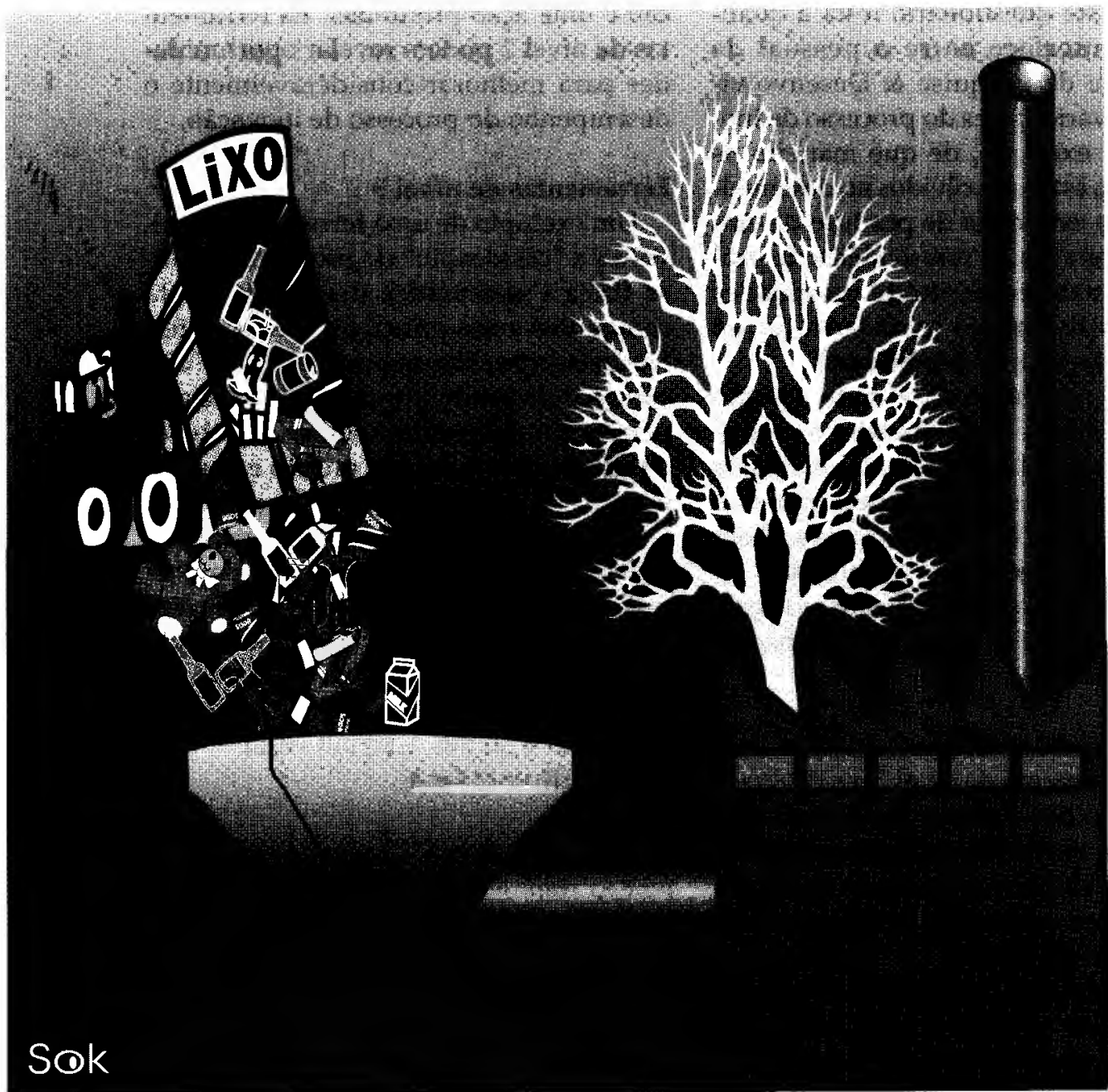

PALAVRAS-CHAVE:

Gerenciamento de resíduos sólidos, política ambiental, ecologia, desenvolvimento sustentável.

KEY WORDS:

Solid waste management, environmental policy, ecology, sustainable development.

^ Economista, Mestre em Administração Pública pela EAESP/FGV, Técnico em Desenvolvimento Organizacional da FUNDAP. 


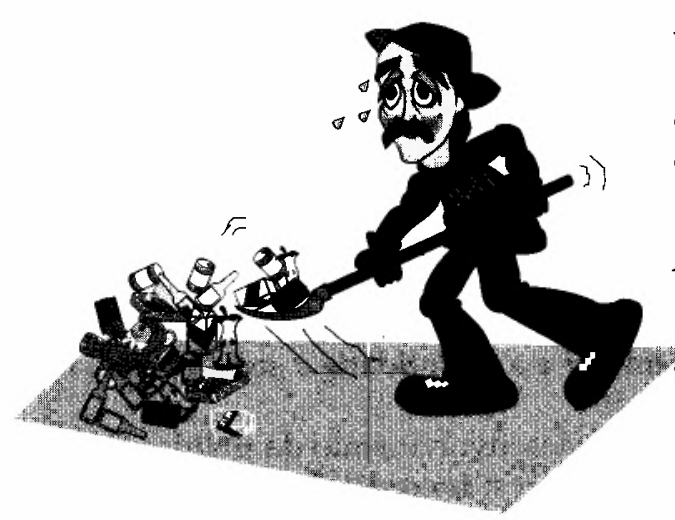

A relação entre resíduos e problemas ambientais é mais evidente no campo dos resíduos sólidos, uma vez que seu grau de dispersão é bem menor do que o dos líquidos e gasosos. É fácil ter uma idéia da dimensão do problema apenas imaginando as quantidades de lixo produzidas em cáda casa ou em cada unidade industrial e que, de alguma forma, devem ser dispostas.

Os resíduos sólidos apresentam outra característica muito importante. Diferentemente dos resíduos líquidos e gasosos, parcela significativa do volume total daqueles sólidos encontra-se nas próprias residências dos centros urbanos, o que permite, teoricamente, imediata contribuição por parte dos habitantes no sentido da minimização de seus efeitos negativos sobre o meio ambiente: a contribuição, por exemplo, de separar os resíduos em suas residências, para recuperação e reciclagem. Assim, numa época de aumento da consciência ambiental, é possível entender, nos países desenvolvidos, o apoio crescente das comunidades aos programas de gestão dos resíduos que estimulem sua recuperação em vez de mera disposição.

$O$ crescente conhecimento das implicações, sobre o meio ambiente, do aumento de volume de resíduos a serem dispostos e mais o aumento da consciência ambiental determinaram uma nova qualificação para o problema.

O termo "lixo" foi substituído por "resíduos sólidos", e estes, que antes eram entendidos como meros subprodutos do
Uma análise das principais mudanças da política de gestão de resíduos sólidos nos países da OCDE face aos novos objetivos da política ambiental.

An analysis of the main changes on waste management in $O E C D$ countries due to the new objectives of environmental policy. sistema produtivo, passaram a ser encarados como responsáveis por graves problemas de degradação ambiental. Além disso, "resíduos sólidos" diferenciam-se do termo "lixo" porque, enquanto este último não possui qualquer tipo de valor, já que é aquilo que deve apenas ser descartado, aqueles possuem valor econômico agregado, por possibilitarem (e estimularem) reaproveitamento no próprio processo produtivo. Estas novas características contribuíram para tornar prioritária, dentro do setor público nos países desenvolvidos, a política de gestão de resíduos sólidos, demandando um comportamento diferente dos setores públicos, produtivo e de consumo.

Este trabalho analisa a gestão de resíduos sólidos, tendo como base as mudanças ocorridas nos países da OCDE (Organização para a Cooperação e Desenvolvimento Econômico). A comparação de um modelo tradicional, um intermediário e um outro, atual, de gestão de resíduos sólidos possibilitou explicitar as principais mudanças ocorridas no período compreendido entre o final da década de 60 até a década de 90 , quando a perspectiva da sustentabilidade é incorporada no gerenciamento desses resíduos gerados nos centros urbanos.

\section{OS MODELOS DE GESTÃO DOS RESÍDUOS SÓLIDOS}

A política de gestão de resíduos sólidos inclui a coleta, o tratamento e a disposi- 
FIGURA 1

Modelo tradicional de tratamento de resíduos sólidos

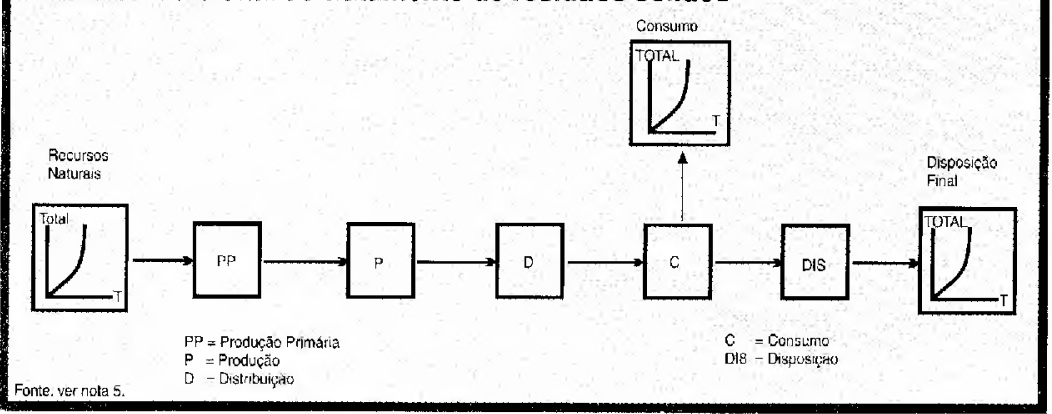

ção adequada de todos os subprodutos e produtos finais do sistema econômico, tanto no que se refere ao lixo convencional como ao lixo tóxico. Hoje há consenso de que, além disso, esta política deve também atuar de forma a garantir que os resíduos sejam produzidos em menor quantidade já nas fontes geradoras.

Os novos objetivos da política ambien-

1. Abfallwirtschaft in wien.

Perspektiven, Magazin für Stadgestaltung und Lebensqualität, Viena, p.1-30, Sept. 1989. de coleta e disposição de resíduos. Em contraposição aos antigos sistemas de tratamento desses resíduos, que tinham como prioridade a disposição destes, os atuais devem ter como prioridade um ecological cycle management, o que significa a montagem de un sistema circular, onde a quantidade resíduos a serem reaproveitados dentro do sistema produtivo seja cada vez maior e a quantidade a ser disposta, menor'.

O desenvolvimento da política de gestâo de resíduos sólidos nos últimos 20 anos, nos países desenvolvidos, permite identificar três fases distintas de prioridades.

A primeira fase, que prevaleceu até o início da década de 70 , é caracterizada pela prioridade em garantir apenas a disposição de resíduos. Este modelo pode ser representado pelo diagrama constante da figura 1.

Como pode ser observado, o crescimento rápido da exploração dos recursos naturais e do consumo nos países desenvolvidos apresentava, como contrapartida, um

\section{OS INSTRUMENTOS DE GESTÃO}

A partir do momento em que os problemas da qualidade ambiental e da sustentabilidade firmaram-se como das variáveis mais importantes no cenário político internacional, os administradores públicos têm-se deparado com a necessidade de selecionar instrumentos mais adequados à luta pela preservaçáo ambiental. A política de gestão de resíduos sólidos não constitui exceção, por isso pesquisadores e representantes do setor público e privado têm debatido constantemente alternativas que induzam à redução efetiva dos resíduos gerados no setor produtivo e de consumo.

Tradicionalmente, a escolha tem sido a utilizaçăo de regulamentos de comando e controle. Essa política envolve a regulação direta do setor público, onde se destacam uma legislação rigorosa e uma política eficiente de fiscalização. Exemplo dessa forma de atuação são os padróes técnicos e operacionais referentes ao design , à construção e à operação de plantas de tratamento de resíduos sólidos. Nos Estados Unidos, por exemplo, o Decreto de Conservação de Recursos e Recuperação (Resource Conservation and Recovery Act - RCRA) bane os lixôes a céu aberto e exige que sejam fechados ou transformados, em prazo determinado, em aterros sanitários. O mesmo decreto define as normas de construção e operação dos aterros de forma a evitar a degradaçāo ambiental. Outro exemplo da atuação governamental é o desenvolvimento de leis para incentivar a redução de resíduos e estimular a reciclagem de materiais. No caso dos consumidores, em alguns estados americanos, as leis exigem que os recicláveis sejam coletados diretamente nas residências, exatamente como se faz com o lixo comum. Outros estados prevêem, ainda, a obrigação da separação de resíduos em determinadas categorias, antes de sua coleta. No caso do setor produtivo, se fortalece a legislação obrigando as empresas a utilizarem determinada porcentagem de material reciclado nas manufaturas dos produtos ${ }^{1}$.
Durante a década de 80 , contudo, a eficiência desses instrumentos tradicionais vem sendo bastante criticada. De um lado, a inflexibilidade dos regulamentos inibe o desenvolvimento de alternativas mais eficientes que possam representar maior ganho ambiental e menores custos para as empresas. Por outro lado, a abordagem reguladora demanda uma infra-estrutura administrativa bem organizada para cumprimento das normas. Uma estrutura que muitas vezes não está suficientemente solidificada nos países em desenvolvimento ${ }^{2}$.

Recentemente, muitos países, especialmente os desenvolvidos, têm implementado instrumentos econômicos na sua política de gestão ambiental. A escolha dos instrumentos, em substituição às regulaçôes de comando e controle, tem como principais objetivos aumentar a flexibilidade, a eficiência e a redução de custos na política de controle de poluiçāo e de exploração racional de recursos naturais. Em teoria, os instrumentos econômicos teriam a capacidade de regular o controle da poluição, tendo como base mecanismos de mercado e, dessa forma, facilitar e tornar o envolvimento governamental mais eficiente e efetivo. Em relaçāo aos instrumentos tradicionais, essa política poderia apresentar diversas vantagens, tais como estimular o desenvolvimento de tecnologias de controle de poluição no setor privado, eliminar a necessidade de elaboração de legislação extensa e detalhada para controle das atividades industriais e prover o governo com receitas para apoiar programas de combate à poluição ${ }^{3}$.

Alguns exemplos de instrumentos econômicos hoje utilizados nos países desenvolvidos demonstram a potencialidade dessa alternativa na condução da política de gestão de resíduos sólidos. As cidades de Washington e Seattle operam, atualmente, um sistema de cobrança variável. Cada morador deve pagar determinada quantia por container de lixo recolhido (um container de 135 litros coletado uma vez por semana custa US\$13.75; cada 
crescimento igualmente rápido do volume dos resíduos a serem dispostos, um fato decorrente da ausência de políticas para reduzir a quantidade de residuos em qualquer das ctapas do sistema produtivo.

Durante a década de 60 e início da de 70, na maioria dos paises da OCDE foram erradicados os últimos lixóes a céu aberto. A maior parte dos residuos era encaminhada para aterros sanitários e incineradores. A partir de meados da década de 70, o movimento ambientalista passou a concentrar, cada vez mais, suas críticas sobre as formas tradicionais de destinação dos residuos sólidos. Os aterros sanitários, que constituem até hoje, em todo o mundo, o meio mais utilizado para a disposição de residuos com algum tratamento, apresentavam problemas. A reduçäo, nos países desenvolvidos, de espaço disponivel para a construção de novos alerros co aumento de problemas relacionados à poluição ambiental (poluição dos lençóis de água subterrâneos) tornavam claro que esta opção já não se constituía na melhor alternativa.

No processo de incineração, as vanta- gens relacionadas à redução do peso e do volume, em 75 e $90 \%$ respectivamente (a quantidade crescente de papel e plástico nos resíduos aumenta seu valor calorífico, tornando o processo de incineração mais eficiente), tinham, como contrapartida, uma cmissão maior de poeira, ácido clorídrico, monóxido de carbono, óxido de nitrogênio, metais pesados e dioxinas na atmosfera ${ }^{2}$. Além disso, as críticas a esse tipo de tratamento de resíduos referiam-se também ao fato de que csses métodos em nada contribuíam para uma redução efetiva dos resíduos sólidos antes da sua disposição.Tal disposição nas formas tradicionais, além de realizada extcrnamente ao processo produtivo, não representava um custo significativo em relação ao custo total na estrutura de produção das empresas, nāo havendo, portanto, estímulo para que estas diminuíssem a geração de resíduos durante o próprio processo produlivo.

$O$ aumento dos problemas ambientais relacionados à disposição de resíduos e à mobilização crescente de diversos atores

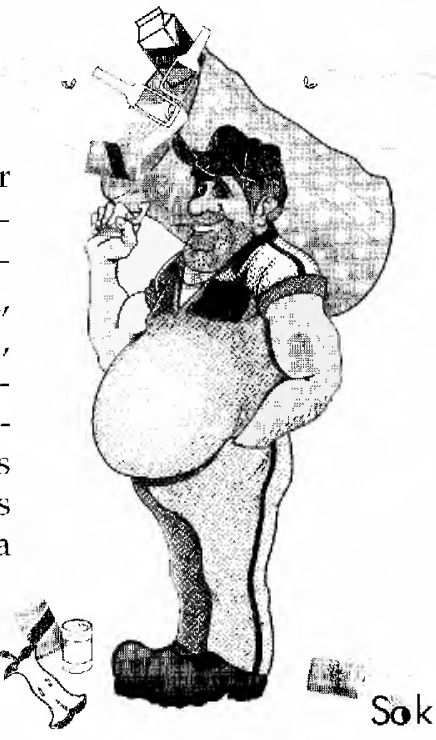

2. KAHRBANDA O.P., STALLWORTHHY E.A. Waste management, towards a sustainable society. London: Gower, 1990. container adicional custa US\$9.00). Quando o número de containers usados mensalmente é reduzido, os residentes são premiados com a diminuição do preço dos serviços de coleta e disposição de resíduos. Com a implementação desse sistema, a cidade de Seattle conseguiu, em pouco mais de um ano, reduzir em $30 \%$ a coleta mensal de resíduos sólidos. A experiência ame ricana mostra que a eficiência desse sistema aumenta, quando a cobrança é instituída paralelamente a um programa de coleta seletiva de resíduos sólidos. É importante ressaltar que, apesar do sucesso do sistema, o mecanismo de "pagar por sacola" (payper-bag) apresenta alguns problemas. $O$ alto custo da fiscalização do sistema, desavenças sobre a base da cobrança e as formas de pagamento são questōes que precisam ser superadas".

A "cobrança para disposição" (dispose charge) é uma segunda modalidade de instrumento economico usada cada vez mais freqüentemente nos países desenvolvidos. Por esse sistema o cálculo do custo de disposição de resíduos em aterros sanitários e incineradores leva em consideraçáo o peso, o tipo de material e a forma de tratamento necessário antes de sua disposição. Em alguns estados americanos, como no caso de Maryland, por resíduos considerados tóxicos, como pneus e óleo, pagam-se taxas mais elevadas. Afetando as empresas em sua estrutura de custos, esse instrumento procura induzir a diminuição da geração de resíduos e sua máxima reciclagem.

Uma terceira modalidade de instrumento econômico é o denominado sistema de depósito-restituição (deposit-refuna system). Essa taxa, que incide sobre o preço fínal do produto para o consumidor, tem o objetivo de estimular a reciclagem e prevenir a poluição. Na maioria das vezes esse instrumento é usado para garrafas de bebida. Nos Estados Unidos, dez estados já implementaram depósitos obrigatórios para garrafas de refrigerante e de cerveja. Segundo Moore, ${ }^{5}$ por esse sistema, 80 a $95 \%$ das garrafas estão sendo entregues voluntariamente nos containers. Cada garrafa devolvida significa a economia de 5 a 10 centavos de dólar. Também adotado na Finlândia, esse sistema permitiu que $90 \%$ das garrafas fossem dirigidas aos containers de reciclagem. Na Suécia, o sistema, usado para latas de alumínio, aumentou a porcentagem de latas devolvidas de 70 para $80 \%$.

No caso das baterias de automóveis, esse sistema também tem gerado bons resultados. Nos Estados Unidos, no estado de Rhode Island, a compra de qualquer bateria obriga o pagamento de uma taxa de depósito no valor de US\$5.00. O consumidor fica isento desse pagamento se a antiga bateria é retornada ao comerciante na compra de uma nova. Os depósitos recolhidos dos compradores eram mantidos pelos comerciantes em uma conta especial. Em 1989, 80\% dos depósitos efetuados foram transferidos para o Estado, demonstrando o alto grau de adesão da comunidade a esse programa. O sistema é considerado um sucesso ${ }^{6}$.

1. BERNSTEIN, JANIS D. Alternative aproaches to pollution control and waste management regulatory and economic instruments, Discussion Paper. Washington: World Bank, 1991, p. 53-61.

2. OPSCHOOR, J., LOHMANN, A., VOS, H. Managing the environment: the role of economic instruments. Paris. OECD, 1994, p. 27-51.

3. Idem, ibidem.

4. BERNSTEIN, JANIS D. Op. cit.

5. MOORE, John L. Using incentives for environmental protection: an overview. Washington D.C.: Library of Congress, 1989.

6. BERNSTEIN, JANIS D. Op. cit. 
na questão ambiental resultaram em mudanças importantes nas principais prioridades do tratamento de resíduos, caracterizando sua segunda fase. Em 1975, os países da OCDE publicaram, pela primeira vez, as prioridades em relação à gestão de resíduos sólidos, nesta ordem:

- redução da produção de resíduos;.

- reciclagem do material;

- incineração com reaproveitamento da energia;

- disposição em aterros sanitários controlados ${ }^{3}$.

Contudo, na prática, os efeitos sobre a gestão de resíduos sólidos acentuaram-se mais significativamente apenas a partir da década de 80 , ainda assim de forma parcial. Se, de um lado, a reduçăo da produção de resíduos continuava como retórica, de outro, a promoção da recuperação e

\section{FIGURA 2}

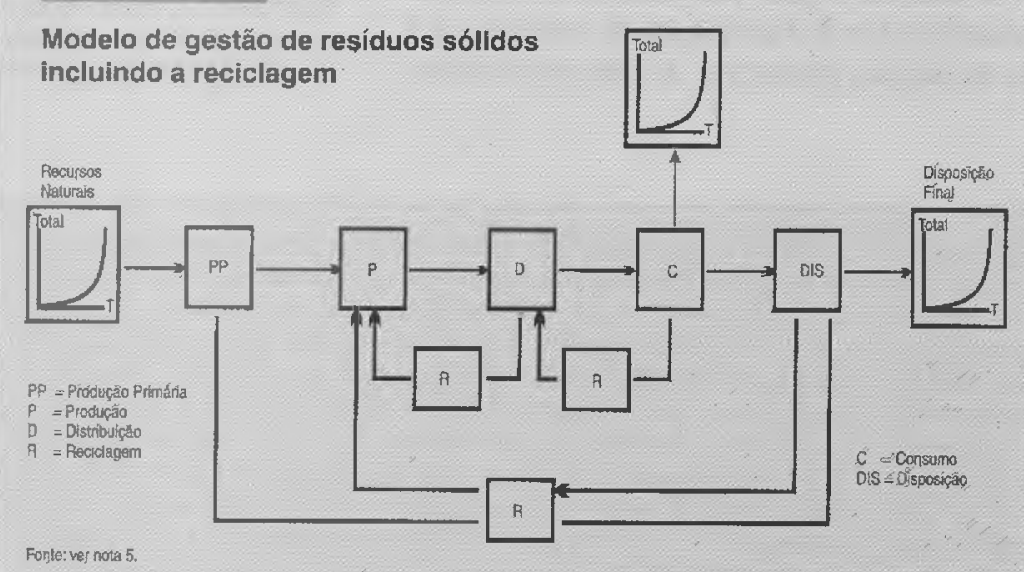

3. EG-UMWELTPOLITIK, ÖSTERREICH UND FUROPÄISCHEN GEMEISCHAFT Österreichisches, Aussenmini-sterium Viena, Feb. 1993.

4. Abfallwirtschaft in wien. Op. cit.

reciclagem dos materiais passou a ser prioridade nessa segunda fase da política de gestão de resíduos.

Por meio do desenvolvimento de legislação e instrumentos econômicos estimulando o uso de produtos reciclados (ver box Os instrumentos de gestáo) e, ainda, de um apoio cada vez maior da população, desenvolveu-se um mercado rentável para os produtos reciclados durante a década de 80. Esse sistema é representado no diagrama da figura 2.

Nessa fase, para a garantia e reaproveitamento dos resíduos, são estabelecidas novas relações entre consumidores finais e produtores assim como entre distribui- dores e consumidores. A reciclagem realizada em etapas diferentes do processo produtivo significa o crescimento mais lento do consumo de recursos naturais e do volume de resíduos a serem dispostos, devido ao reaproveitamento de uma parcela dos resíduos que, na fase anterior, teria como destino aterros sanitários e incineradores.

Ao final de década de 80 , surgiram as primeiras críticas ao estímulo apenas à recuperação e reciclagem dos resíduos. As vantagens atribuídas à reciclagem de materiais, tais como menor consumo de energia e redução do volume de resíduos, deveriam ser relativizadas, uma vez que o processo de reciclagem, além de produzir resíduos, necessitava de matérias-primas e energia consideráveis. Além disso, percebeu-se que o incentivo da política de reciclagem, apesar de considerada ainda hoje um importante instrumento de política de gestão de resíduos sólidos, da forma como estava sendo conduzida acabava possibilitando uma externalização dos custos para as empresas, em relação ao reaproveitamento dos resíduos. (Nesse processo não existe vinculação entre resíduos gerados e fonte geradora. Os resíduos são coletados - na maior parte das vezes por terceiros - e revendidos.) Dessa forma, mantendo o custo com o reaproveitamento e reciclagem dos produtos, externamente ao processo produtivo, não havia estímulo para que a redução de resíduos desnecessários, já no início do processo produtivo, fosse uma prioridade para as empresas. Por fim, além da constatação dos limites da reciclagem, ampliaram-se também as críticas à falta de uma política específica para tratamento de resíduos tóxicos e ao aumento das exportaçōes desse material para disposição final em países em desenvolvimento.

O final de década de 80 marca o estabelecimento, nos países desenvolvidos, de novas prioridades em relação à gestão de resíduos sólidos. Na terceira fase, antes de diminuir a produçāo de determinados bens, é prioritário que eles nāo sejam sequer gerados. Em vez de serem reciclados, é prioritário que sejam reutilizados. Antes de depositá-los em aterros sanitários, é prioritário reaproveitar a energia presente nos resíduos, por meio de incineradores ${ }^{4}$. 
Assim, a prioridade passa a ser a redução do volume de resíduos já no início do processo produtivo, continuando nas demais etapas da cadeia produtiva. Além disso, produtos com dificuldade de reciclagem devem ser devolvidos aos fabricantes, que devem ser responsáveis por seu tratamento e disposiçāo. Esse sistema é representado no diagrama da figura 3 .

Esse modelo da figura 3 implica uma série de alterações no comportamento dos diversos atores envolvidos em todas as etapas do processo, muitas ainda bastante difíceis de serem alcançadas, pois prioridades como evitar e reduzir a produção de resíduos na própria fonte geradora exigem mudanças significativas já no processo produtivo.

O exito desse processo, portanto, depende de medidas que atuem desde a fase do design do produto. Os novos produtos devem priorizar a utilização de material que possa ser, em primeiro lugar, reaproveitado ou, quando isto nāo for possível, reciclado. Além disso, os produtos devem ter uma vida longa e apresentar facilidade para serviços de reparaçāo ${ }^{5}$.

Uma segunda mudança refere-se às alterações no modelo de produção. O processo de produção deve ser realizado de forma a utilizar menor quantidade de energia e matérias-primas, além de produzir menos resíduos. Sāo necessárias políticas que estimulem o emprego de nonwaste, low-waste e clean technologies ${ }^{6}$.

Quanto ao sistema de distribuição dos produtos, priorizam-se também embalagens de transporte que possam ser reutilizadas ou recicladas, tais como containers; pallets e outras, retornáveis, e não do tipo one way.

O setor de consumo também representa parte importante desse processo. Modificaçōes dos hábitos de consumo, como priorizar a compra de produtos que utilizem menos embalagens ou produtos que possam ser reciclados, constituem exemplos da contribuição deste setor.

Com a adoção dessas medidas e da montagem desse sistema complexo, espera-se alcançar os seguintes objetivos:

- redução do consumo de recursos naturais, de material e energia;

- reduçāo da poluiçáo decorrente do processo de produção;

- reduçāo do volume de resíduos.

\section{FIGURA 3}

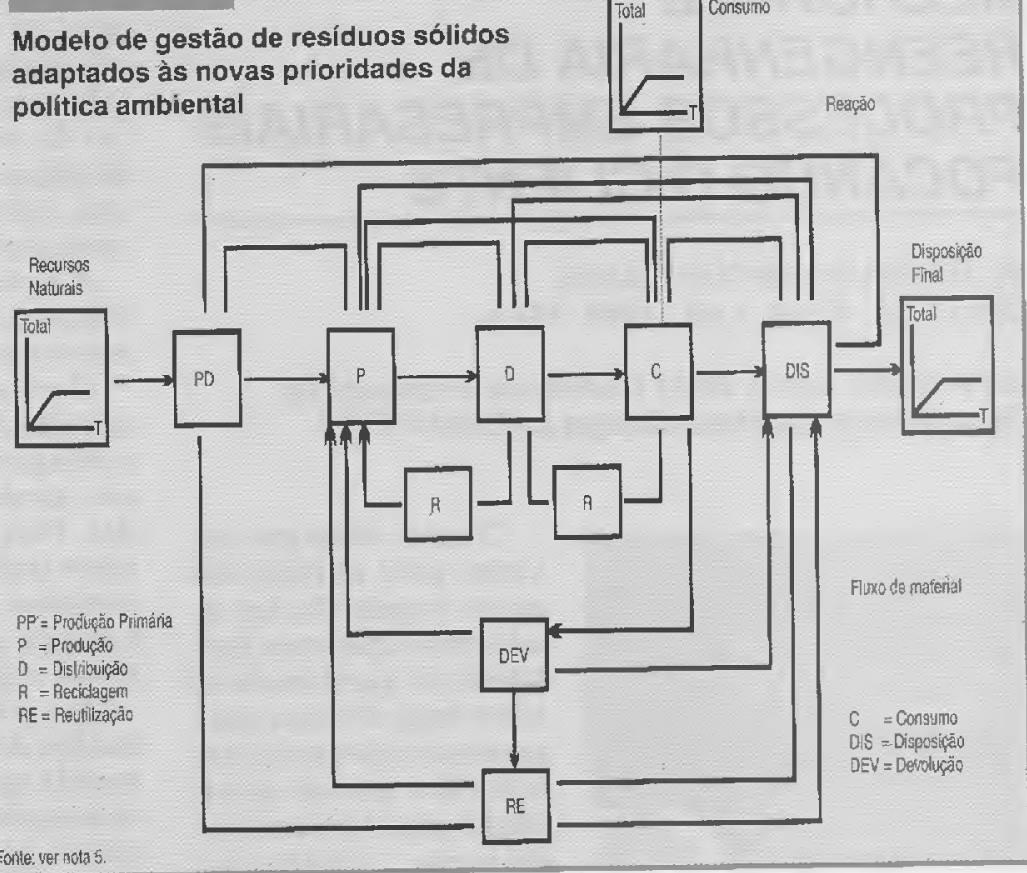

Fonte: ver aota 5 .

Assim, é possível resumir as diretrizes da atual política de gestão de resíduos por meio das seguintes prioridades:

- evitar ou, quando não for possível, diminuir a produçāo de resíduos;

- reutilizar ou, quando não for possível, reciclar resíduos;

- utilizar a energia presente nos residuos;

- "inertizar" e dispor os resíduos?.

As novas prioridades da atual política de gestăo de resíduos sólidos incorpora a dimensão da sustentabilidade por duas razōes principais. Primeiro, é possível minimizar o processo de degradação ambiental antes que isto ocorra, à medida que se evita a produçāo de determinados resíduos, reaproveita-se parcela destes e "inertiza-se" o restante. Segundo, ao gerenciar a produção de resíduos sólidos em todas as fases do sistema econômico, e não apenas se concentrando no tratamento final destes, a atual política de gestāo de resíduos sólidos tem como objetivo garantir, a longo prazo, uma estabilização da demanda por recursos naturais e do volume final de resíduos a serem dispostos, fatores estes fundamentais na busca do desenvolvimento sustentável. $\square$

\section{8}

5. VOGEL, G. Die Abfall und die Umweitproblematik aus technoökonomischer und ökologischer Sicht, Viena: Wirtschaftsuniversität, März 1993, p. 1-9.

\section{Idem, ibidem.}

7. Abfallwirtschafts in Wien. Op. cit.

Artigo recebido pela Redação da RAE em janeiro/1995, avaliado em janeiro e maio/1995, aprovado para publicação em maio/1995. 